\title{
El giro teológico como retorno a los orígenes: La fenomenología de la excedencia
}

\author{
Roberto J. Walton*
}

Resumen: La fenomenología muestra desde su comienzo mismo una tendencia teológica. Mientras que Husserl desarrolló una teología filosófica vinculada a la teleología infinita de la comunidad trascendental, Scheler elaboró un saber de salvación como participación en el ens a se. A su vez, Heidegger se refirió al último Dios como el comienzo de las inconmensurables posibilidades de nuestra historia. Sobre este trasfondo, que realza la excedencia de posibilidades, el giro teológico en la fenomenología reciente puede ser entendido como un intento de centrar la demasía en reinos particulares como la intersubjetividad, la interioridad y el mundo, o bien en la condición de los fenómenos refiriéndolos a una lógica de la sobreabundancia o a una máxima saturación.

Palabras clave: Acrecentamiento, teleología, lo inconmensurable, lo inmemorial, autotrascendencia, sobreabundancia.

Abstract: Phenomenology shows from its very beginning a theological tendency. Whereas Husserl developed a philosophical theology linked to the infinite teleology of the transcendental community, Scheler worked out a knowledge for salvation that participates in the ens a se. Heidegger, in turn, referred to the last God as the beginning of immeasurable possibilities for our history. Against this background, which enhances an excess of possibilities, the theological turn in recent phenomenology can be understood as an attempt to focus the surplus on particular realms such as intersubjectivity, interiority, and the world, or on the condition of phenomena as such, by referring them to a logic of superabundance or to a maximal saturation.

Key-words: Heightening, teleology, the immeasurable, the inmemorial, self-transcendence, superabundance.

Résumé: La phénoménologie montre depuis son commencement même une tendance théologique. Alors que Husserl a mis en place une théologie philosophique en relation avec la théologie infinie de la communauté transcendantale, Scheler, de son côté, a élaboré un savoir du salut telle une participation au ens a se. Pour sa part, Heidegger fait référence au dernier Dieu comme le commencement des possibilités incommensurables de notre histoire. Avec cet antécédent qui met en valeur l'excédence des possibilités, le tournant théologique dans la phénoménologie récente peut être entendue comme une manière de centrer l'excès dans des règnes particuliers comme l'intersubjectivité, l'intériorité et le monde, ou encore, dans la condition des phénomènes en les rapportant à une logique de la surabondance ou à une saturation maximale.

Mots-clés: Accroissement, théologie, l'incommensurable, l'immémorialité, autotranscendance, surabondance.

* Universidad de Buenos Aires, Argentina (grwalton@fibertel.com.ar). 
Una primera reflexión que merece el llamado giro teológico es que no es otra cosa que un modo de retornar al origen ya que el problema de Dios ha estado en el centro de la fenomenología desde un comienzo, ya sea en una dirección ontoteológica a través del pensamiento de Edmund Husserl y Max Scheler, ya sea por medio de un cuestionamiento de la ontoteología en la meditación de Martin Heidegger. A estas cuestiones dedico la primera parte de este trabajo a fin de introducir el tema del acrecentamiento con participación decisiva de Dios como una cuestión que se reitera en las perspectivas fenomenológicas posteriores.

Además, sin que podamos aquí detenernos en esto, se debe recordar que en la fenomenología francesa, a la cual se tiene en vista principalmente cuando se habla de giro, el problema se mantuvo siempre presente. Gabriel Marcel habla de "grados de saturación extremadamente variables" ${ }^{\prime 1}$ en la experiencia y de la filosofía como "sobre-elevación de la experiencia" 2 . Considera que la fenomenología abre el camino a una "reflexión hiperfenomenológica que es la metafísica misma" ${ }^{3}$. Así se ingresa en la zona metaproblemática del misterio que atañe a un más allá o trascendencia. Si bien no se confunden con los misterios revelados, los misterios filosóficos implicados en la experiencia humana solo pueden ser reconocidos "por una suerte de irradiación fecundante de la revelación misma, $[\ldots]^{\prime \prime}$. Por otro lado, Henry Duméry considera que, respecto de la religión, la fenomenología es un instrumento "precioso" e incluso "irreemplazable" porque cumple un "cuádruple servicio" a través de sus componen-

1 G. Marcel, Le mistère de l'être, Paris, Association Présence de Gabriel Marcel, 1997, p. 64.

2 G. Marcel, Essai de philosophie concrète, Paris, Gallimard, 1967, p. 124.

3 Ibídem, p. 121 y ss. Cf. G. Marcel, Être et avoir, Paris, Aubier-Montaigne, 1968, vol. 1, pp. 178, 189 y 198.

4 Ibídem, p. 125. tes fundamentales: la epojé sustrae la cuestión del valor de la religión a cualquier presupuesto interpretativo; la intencionalidad respeta lo sagrado porque nos lanza fuera de la propia subjetividad; la intuición de esencias posibilita una manifestación de las significaciones del fenómeno religioso; y el análisis constitutivo permite desvelar estratos de sentido ${ }^{5}$. Este autor describe la religión como el descubrimiento de una excedencia y de un acrecentamiento de exigencia: "La religión es el descubrimiento de una demasía (surplus) que se debe añadir a todo pensamiento, a toda acción, para que sigan siendo válidos, el descubrimiento de un acrecentamiento (surcroît) de exigencia que ningún objeto, ningún bien finito, puede apaciguar". En consecuencia, el hombre religioso es aquel que ha alcanzado la conciencia de sus límites y de su ilimitación, esto es, aquel que obra con esa sobreabundancia a la que llama gracia: "[...] lo que hace lo hace siempre con una sobreabundancia de fuerza y de luz que permanece en él como un excedente (excédent) inempleado" ${ }^{\prime 6}$.

Fuera del ámbito francés se pueden mencionar las preocupaciones de Jan Patocka por describir, junto a los movimientos de arraigo en un hogar y de lucha por la preservación de la existencia, un tercer movimiento de la vida que suprime la disolución en la objetividad y supera toda figura finita en el mundo en una transubstanciación de la vida mediante la entrega recíproca al prójimo. Mientras que el arraigo implica una vida libre en relación consigo mismo, pero finita en razón de la naturaleza de las cosas y tareas, y la prosecución entraña una vida finita y a la vez encadenada a la or-

5 Cfr. H. Duméry, Critique et religion. Problèmes de méthode en philosophie de la religion, Paris, Societé d'Éditions d'Enseignement Supérieur, 1957, p. 221.

6 H. Duméry, Philosophie de la religion. Essai sur la signification du christianisme. II: Catégorie de foi, Paris, Presses Universitaires de France, 1957, pp. 287 y ss. 
ganización de la vida relativa a la satisfacción de las necesidades, el descubrimiento de sí lleva a una vida a la vez infinita y libre, es decir, una vida que tiene su morada en la infinitud de la solidaridad y la entrega: "Manifiesto mi ser como in-finito renunciando íntegramente a mi ser finito, dándolo íntegramente al otro, que me devuelve su ser en el que el mío está contenido" ${ }^{\prime 7}$. La entrega de sí implica que el cielo y la tierra están sujetos a un "estremecimiento" por el que se convierten en "el teatro de algo 'más elevado", es decir, se descubre que "tienen un trans, un más allá" ${ }^{8}$.

Lo que puede considerarse decisivo en la fenomenología más reciente es la tematización del concepto de excedencia en relación con un ámbito particular como sucede en las fenomenologías de Emmanuel Lévinas, Michel Henry y Heinrich Rombach, o con una reflexión sobre el fenómeno en cuanto tal y su estremecimiento como es el caso de Paul Ricoeur y Jean-Luc Marion. A esta cuestión está dedicada la segunda parte del trabajo.

\section{Los orígenes}

\section{1. El acrecentamiento de la razón y el amor}

En su carta a E. Parl Welch, de julio de 1933, luego de referirse a cuestiones relacionadas con la vida ética, la teleología y la auténtica humanidad, Husserl escribe: “Así, la conclusión superior para los problemas de la filosofía fenomenológica es la pregunta por el 'principio' de la teleología concretamente descubierta en sus estructuras universales. De acuerdo con esto, el 'problema constitutivo' superior es la pregunta por el ser de lo ‘supraente' (das Überseiende), precisamente por el ser de este principio que hace posible la existencia de una totalidad en sí concordante de la intersubjetividad trascendental con el mundo constituido a través de ella, por lo

7 J. Patocka, Le monde naturel et le mouvement de l'existence humaine, Phaenomenologica 110, traducción de E. Abrams, prefacio de H. Declève, Dordrecht/Boston/London, Kluwer Academic Publishers, 1988, p. 40.

8 Ibídem, pp. 10 y ss. cual se lo podría designar platónicamente como Idea del Bien" ${ }^{\prime 9}$. La teleología tiene un aspecto fáctico que escapa a la fenomenología eidética. Recordemos que, junto a la ontología o filosofía primera que se ocupa de las esencias, Husserl desarrolla una metafísica o filosofía segunda cuyo tema es "la problemática de la irracionalidad del factum trascendental que se expresa en la constitución del mundo fáctico y de la vida fáctica del espíritu, esto es, metafísica en sentido nuevo"10. Husserl menciona como temas de la metafísica la constitución del mundo fáctico en su estrato de naturaleza y la constitución de la vida fáctica del espíritu. Según Husserl, el darse de una de las formas posibles que se encuentran en disyunción bajo una estructura eidética configura para la conciencia algo dado que no puede ser explicado por ella, es decir, un factum irracional. Diferentes formas esenciales con sus diversas legalidades apodícticas delimitan marcos de posibilidades para la conciencia, es decir, dejan abiertas variadas realizaciones en una conciencia fáctica. $Y$ la realización que nos sale al encuentro es contingente porque escapa a las necesidades establecidas por las esencias e implica que ese mundo podría no ser o bien ser de otra manera. En función de las leyes normativas establecidas a priori por las esencias, Husserl considera que "no es 'necesario' que deba producirse un orden de conciencia unitario y por ende racional, que deba poder presentarse una naturaleza, y una cultura, y un despliegue de la cultura en el sentido de una cultura ideal. ¿O hay para ello fuentes propias de necesidad? Esto significaría demostrar a Dios"11.

Husserl se refiere a la teleología inherente al desenvolvimiento de la razón dentro de la comunidad trascendental de las mónadas: “La voluntad absoluta universal que vive en todos los sujetos trascendentales y hace posible el ser individual concreto de la omnisubjetividad tras-

9 E. Husserl, Briefwechsel, Husserliana-Dokumente III, edición de K. Schumann y E. Schuhmann, Dordrecht/Boston/London, Kluwer Academic Publishers, 1999, vol. 6, p. 461.

10 E. Husserl, Erste Philosophie (1923/24). Zweiter Teil: Theorie der phänomenologischen Reduktion, Rudolf Boehm (ed.), Husserliana VIII, Den Haag, Martinus Nijhoff, 1956, p. 188 n.

11 E. Husserl, Manuscrito B I 4, 2 s. Citado por I. Kern, Husserl und Kant, Phaenomenologica 16, Den Haag, Martinus Nijhoff, 1964, pp. 299 y ss. 
cendental, es la voluntad divina, que empero presupone la intersubjetividad total [...] como una capa estructural sin la cual esta voluntad no puede ser concreta"12. Y subraya que, por esta razón, la comunidad "se encuentra en el proceso de un acrecentamiento (Steigerung) in infinitum $^{\prime \prime 13}$. Todo el despliegue racional apunta a un polo según el cual, en el terreno teórico, el mundo se confirma plenamente y es conocido de un modo cada vez más pleno, y, en el terreno práctico, la comunidad trascendental se convierte en una comunidad de amor. Queda esbozada la noción de una Idea teleológica que está más allá de la conciencia de la conciencia constituyente y de la objetividad constituida -es a la vez "supratrascendental" y "supramundana"-, y proporciona una explicación para lo que aparece como un hecho contingente, esto es, la racionalidad de la naturaleza y el desarrollo de la razón en la historia tanto en su vertiente teórica como en su vertiente práctica. Se trata de "la Idea de una vida que impera a través de todas las finitudes y facticidades, y que a través de toda vida fáctica es la realización ideal hacia el infinito de una vida absolutamente perfecta $[. . .]^{\prime 14}$.

La pregunta se plantea ante el problema de la posible pérdida de racionalidad en las operaciones que llevan a cabo la constitución concordante del mundo y la constitución armónica de una comunidad ética. Husserl considera que la tendencia de cada sujeto a una coincidencia intersubjetiva a través de la corrección de sus operaciones, y la norma racional que está implícita en este proceso en el que se descarta todo lo que no se ajusta a esa tendencia, ponen de manifiesto una meta que orienta el desarrollo y también una seguridad de que la historia no se apartará del camino hacia ella: "Dios no es en sí mismo la totalidad monádica, sino la entelequia que reside en ella en tanto Idea del telos infinito de un despliegue, del telos de una 'humanidad' a partir de la razón absoluta en tan-

12 E. Husserl, Zur Phänomenologie der Intersubjektivität. Texte aus dem Nachlass. Dritter Teil: 1929-1935, Iso Kern (ed.), Husserliana XV, Den Haag, Martinus Nijhoff, 1973, p. 381.

13 Ibídem, p. 610.

14 E. Husserl, Manuscrito E III 4, p. 61. Citado en A. Diemer, Edmund Husserl. Versuch einer systematischen Darstellung seiner Phanomenologie, Meisenheim am Glan, Anton Hain, 1956, pp. 375 y ss. to necesariamente reglante del ser monádico y reglante a partir de su propia decisión libre"15. Un principio de perfección inmanente a la comunidad intermonádica asegura el desarrollo de la razón en la humanidad, no mediante una imposición externa, sino de tal modo que la mónada individual se encuentra "motivada"16 para orientarse según el telos. Lo que Husserl subraya es la posible irracionalidad del factum junto con el resorte y el garante de una síntesis coherente tanto en el plano teórico como en el práctico $^{17}$.

En el proyecto de una carta con destinatario anónimo del año 1935, Husserl escribe: “El hombre vive como ser finito, pero es finito en el horizonte de la infinitud. Su destino es llegar a ser plenamente consciente de esta infinitud y asumirla con plena conciencia [...] en dirección hacia el Ideal absoluto que mueve concretamente su espíritu en tanto Dios de la religión" ${ }^{18}$. En relación con la comunidad ética, Husserl se ocupa del amor al prójimo, y subraya que el encontrarse recíproco de cada sujeto en el horizonte del otro es lo que caracteriza al amor ético que se inspira en el infinito amor de Cristo a todos los hombres. En este terreno, destaca el carácter de amonestación y evocación del propio amor que tienen las palabras de Cristo: "Ellas se apoderan de mí, me inspiran, me elevan. Pueden amonestarme, hacerme sentir mi indignidad, pero esta amonestación, como la de un amigo o maestro reverenciado, es una amonestación del amor que me habla en 'lo más interior del alma' y como acto de amor despierta en mí el amor, o que, desde un comienzo, mueve el yo en el medio de mi amor y del amor recíproco" $^{\prime 19}$. Y al señalar que la figura de Cristo

\footnotetext{
5 Husserl, Zur Phänomenologie ..., ob. cit., III, p. 610.

6 Husserl, Erste Philosophie (1923/24)..., ob. cit, p. 258.

17 "El telos es el resorte secreto de todo el despliegue, y es también el garante de que el despliegue no se extraviará o detendrá. El telos transhistórico y supratemporal es, pues, un concepto metafísico último. Husserl no vacila en identificar este telos con la divinidad" (S. Strasser, "Das Gottesproblem in der Spätphilosophie Husserls", Philosophisches Jahrbuch der Görres-Gesellschaft, 67, 1959, p. 136).

18 Husserl, Briefwechsel..., ob cit., vol. 9, p. 521.

19 E. Husserl, Manuscrito. F I 24, 28a. Citado en R. Toulemont, L'essence de la societé selon Husserl, Paris, Presses Universitaires de France, 1962, p. 245. Edmund Husserl, Zur Phänomenologie der Intersubjektivität. Texte aus dem Nachlass. Zweiter Teil: 1921 - 1928, edición de I. Kern, Husserliana XIV, Den Haag, Martinus Nijhoff, 1973, p. 174.
} 
evoca en nosotros un Reino de bienes perfectos y nos proporciona la evidencia de un obrar por pura bondad, Husserl escribe: “[...] poder obrar del mismo modo sería una bienaventuranza, y debería despertar en mí amor y el amor más puro. Y Cristo mismo está ahí para mí no solo como el que exige de esta manera, sino como el perfectamente bueno, como el que contempla la pura bondad, vuelto en un puro amor a todos los hombres como semilleros de un puro bien posible, como el que comprende todo y perdona todo, y solo puedo concebirlo para mí como la encarnación de la pura bondad del hombre: como el hombre ideal" ${ }^{20}$.

En suma: Husserl se refiere a un acrecentamiento que significa un ascenso del hombre, motivado por Dios, en el camino de la razón y del amor, y que, en este último aspecto, encuentra su modelo en Cristo.

\subsection{La creciente compenetración de espíritu e ímpetu}

Según Scheler, el hombre puede alcanzar tres clases de saber: el saber de dominio, el saber de esencia y el saber de salvación. La jerarquía de los tres tipos de saber corresponde a la jerarquía objetiva de las modalidades de valor, es decir, los valores vitales, los valores espirituales y los valores de lo sagrado. Ha llegado el tiempo de una complementación entre los tres saberes con la subordinación del saber de dominio al saber de esencia, y de éste al saber de salvación: "Pues todo saber es en última instancia de la Deidad y para la Deidad"21.

El saber de dominio o saber para el rendimiento está orientado hacia el poderío técnico sobre la naturaleza, la sociedad y la historia, y procura excluir la relatividad de lo existente a un determinado mundo circundante particular a fin de indagar lo que es relativo a la organización de todos los hombres, es decir, al hom-

20 E. Husserl, Aufsätze und Vorträge (1922-1937). Mit ergänzenden Texten, edición de Th. Nenon y H. Rainer Sepp, Husserliana XXVII, Dordrecht/Boston/London, 1989, p. 100.

21 M. Scheler, Späte Schriften, Gesammelte Werke 9, Bern/München, Frankke, 1976, p. 119. bre como ser viviente en general. Un segundo tipo de saber es el saber de esencia o saber para la formación personal. Surge de la admiración ante la configuración constante de las cosas, y corresponde a la "filosofía primera" de Aristóteles, es decir, la ciencia de la estructura esencial de todo lo que es. Nos proporciona la ontología esencial del mundo y el sí-mismo y está al servicio de la transformación del hombre. No exhibe una actitud de dominio frente al mundo porque prescinde del ser-ahí o existencia real de las cosas y de todo ser-así contingente, es decir, de todo aquello que resiste a nuestro impulso y acción. El saber de esencia tiene dos aplicaciones. Por un lado, delimita los presupuestos superiores de la investigación en cada uno de los ámbitos de las ciencias positivas. Por el otro constituye un "trampolín" para la metafísica: "Todo lo que se muestra como auténtico ser esencial, y auténtica estructura esencial del ser, ya no es explicable de un modo positivo-científico y configura una 'ventana' (como Hegel lo expresó muy plásticamente) hacia los atributos del Ens a se"22.

La tercera clase de saber es el saber para la salvación que permite a nuestro núcleo personal participar en el fundamento de todas las cosas: "Así como todo 'saber' y todo conocimiento es un modo de participación del sujeto cognoscente en un ente que es y subsiste independientemente de él mismo, así también la 'metafísica' es por así decirlo el eterno intento del hombre por participar mediante su razón espontánea en lo 'absolutamente real' de las cosas y de sí mismo $[\ldots]^{\prime 23}$. La participación implica un conocimiento de lo real, y se diferencia del mero conocimiento de la estructura esencial del mundo. Así aparece una distinción análoga a la trazada por Husserl entre ontología y metafísica. El pasaje por las esencias que se individualizan en hechos contingentes constituye también un momento previo y necesario para elaborar una metafísica, que se origina en el asombro ante la contingencia del hecho de que haya un mundo y el hombre sea.

22 M. Scheler, Schriften aus dem Nachlass. Band 2: Erkenntnislehre und Metaphysik, Gesammelte Werke 11, Bern/München, Francke, 1979, p. 127.

23 Ibídem, p. 11. 
Según Scheler, luego de los análisis de primer orden centrados en las esencias, la metafísica culmina en la metafísica de segundo orden o metafísica de lo absoluto, esto es, el Ens a se cuyos atributos cognoscibles por nosotros son el ímpetu y el espíritu. El devenir del mundo consiste en un proceso por el cual los dos atributos del fundamento se compenetran. Espíritu e ímpetu son atributos de actividad de "lo originariamente uno cuya eterna autoposición posibilita y hace necesaria la unidad funcional de ambas actividades" ${ }^{\prime 24}$. El atributo espiritual del Ens a se no posee ningún poder creador o fuerza originaria. Es una plenitud de posibilidades, incapaz por sí sola de lograr efectos, y, para realizarlas, debe recurrir al ímpetu. Esta Deitas no puede efectivizar lo que piensa, ama o proyecta volitivamente sin coaligarse con el ímpetu en tanto capacidad activa o principio creador de la realidad y plasmador de los elementos contingentes que sensibilizan las esencias en la multiplicidad espacio-temporal. En ausencia de esta cooperación, el atributo espiritual queda restringido al ámbito de lo posible como capacidad pasiva para producir ideas, valores y fines. Y en la cooperación se desenvuelve como un principio limitador que mantiene la realidad contingente en el marco de lo esencialmente posible.

Mientras que el espíritu con su visión es originariamente impotente, el ímpetu con su potencia es originariamente demoníaco, esto es, ciego frente a las ideas y los valores, $y$, por tanto, se encuentra más allá del bien y el mal. En el devenir del mundo, que es también el devenir del Ens a se, se produce una idealización del ímpetu o espiritualización de la vida, y una vivificación de la idea o realización del espíritu. Este proceso implica "una creciente compenetración (steigende Durchdringung) de estos dos atributos de actividad" que a la vez implica una "creciente espiritualización (wachsende Vergeistigung)" para el ímpetu y una "creciente obtención de poder y fuerza (wachsende Macht- und Kraftgewinnung)" para el espíritu ${ }^{25}$. Se trata de un proceso metafí-

24 Ibídem, p. 189.

25 Scheler, Späte Schriften..., ob. cit., p. 81. sico idéntico considerado ya sea "desde arriba" en la perspectiva del espíritu o la esencia, ya sea "desde abajo" en la perspectiva del ímpetu o de la existencia. Tan solo al final de este proceso se encuentra la omnisciencia y omnipotencia -sobre las que insiste el teísmo- luego de una historia que consiste en "el devenir de la 'Deidad' en un 'Dios'" ${ }^{\prime 26}$. La historia del mundo es la manifestación temporal de la distensión de la oposición originaria entre espíritu e ímpetu en el fundamento del mundo. De ahí la siguiente definición: "Metafísica es ir tras los pasos de Dios en el mundo e ir con él" ${ }^{27}$. Así, la historia del hombre está "entrelazada" 28 en el devenir de Dios.

Scheler se ocupa de un acrecentamiento inherente a la espiritualización y vivificación del los atributos del Ens a se en un proceso en que participa el hombre según un peculiar velle, amare in Deo, cognoscere in lumine Dei. Puesto que se produce una autoidentificación del ente humano con la orientación espiritual de los actos de la Deidad de modo que el centro personal de actos se convierte en una concentración del espíritu divino, toda la cultura y la historia tienen un sentido para la salvación del hombre en Dios. De manera que el hombre es salvado a la vez que contribuye a salvar a Dios de su tensión interna. Y dado que, en el espíritu del hombre, el Ens a se toma conciencia de su atributo espiritual, Scheler puede afirmar que Dios y el hombre son, pues, "compañeros de su destino, sufriendo y sobreponiéndose, algún día tal vez venciendo" ${ }^{\prime 2}$.

\subsection{Las inconmensurables posibilidades}

Según Heidegger, la ontoteología -terreno en que se desenvuelve el pensamiento de Husserl en una vertiente teísta y Scheler en una vertiente panenteísta- sustituye al Dios divino por el fundamento último de la metafísica. Por eso es necesario dar un paso atrás respecto de la

\footnotetext{
Ibídem, p. 71.

Scheler, Schriften ..., ob. cit., p. 92.

Scheler, Späte ..., p. 101.

Ibídem, p. 162.
} 
concepción del ente supremo y la causa sui que, como lo último de una serie, funda los entes en general. Esta noción supone para Heidegger el olvido del ser que caracteriza a la metafísica, y solo la verdad del ser permite pensar lo sagrado y a partir de ahí la esencia de la divinidad y de aquello que se nombra con la palabra "Dios": "La falta de Dios y de lo divino es ausencia. Ahora bien, la ausencia no se identifica con la nada sino que es precisamente la presencia, de la que primero hay que apropiarse, de la oculta plenitud de lo sido, y de lo que así reunido despliega su esencia, de lo divino en el mundo griego, en las profecías judías, en la predicación de Jesús" ${ }^{\prime 30}$.

Heidegger despliega una "fenomenología de lo inaparente" ${ }^{\prime 31}$ que se ocupa de aquello que mantiene una ocultación. Esta fenomenología encuentra "lo más inaparente de lo inaparente $^{\prime \prime 2}$ en el Ereignis o acontecimiento apropiante que realiza una doble apropiación en el sentido de llevar términos vinculados a lo que tienen de propio. Por un lado, el Ereignis es "la apropiación (Er-eignung) del Dasein por medio del Seyn y la fundación de la verdad del Seyn en el Da-sein)" ${ }^{\prime 3}$. Esto significa que el hombre pertenece al Seyn y corresponde a su interpelación en un viraje (Kehre), y que el ser necesita del hombre y lo interpela en un contra-viraje (Wieder-Kehre): "El Seyn necesita del hombre para esenciarse, y el hombre pertenece al Seyn para consumar su más extrema determinación como Da-sein" ${ }^{\prime 34}$. En medio de ambos, de una recíproca oscilación o contrabalanceo, se despliega el Ereignis. Por otro lado, Heidegger se ocupa del "Dios extremo" o "último Dios" que, requiere del Ereignis como un "entre" o "punto medio" para su correspondencia y contraste

30 M. Heidegger, Vorträge und Aufsätze (1936-1953), Gesamtausgabe 7, Frankfurt am Main, Vittorio Klostermann, 2000, p. 185. Cfr. M. Heidegger Wegmarken (1919-1961), Gesamtausgabe 9, Frankfurt am Main, Vittorio Klostermann, 1976, pp. 349 y ss.; y M. Heidegger, Identität und Differenz, Gesamtausgabe 11, Frankfurt am Main, Vittorio Klostermann, 2006, p. 77.

31 lbídem, p. 399.

32 M. Heidegger, Unterwegs zur Sprache (1950-1959), Gesamtausgabe 12, Frankfurt am Main, Vittorio Klostermann, 1985, p. 247.

33 M. Heidegger, Beiträge zur Philosophie (Vom Ereignis) (1936-1938), Gesamtausgabe 65, Frankfurt am Main, Vittorio Klostermann, 1989, p. 202. Seyn es una antigua forma de Sein (ser) que mantenemos sin traducir.

34 Ibídem, p. 251 con el hombre: "El Ereignis trans-apropia (übereignet) el Dios al hombre en la medida en que apropia-asigna (zueignet) este al Dios"35. Heidegger afirma que Dios necesita del ser y también del hombre como fundador de la verdad del ser: "El Dios no es 'siendo' ni 'no siendo', tampoco es equiparable al Seyn sino que el Seyn se esencia tempo-espacialmente como ese 'entre' que nunca puede estar fundado en el Dios, pero tampoco en el hombre como ante-la-mano y viviente, sino en el Da-sein" ${ }^{\prime 3}$.

El tema de la excedencia aparece de dos maneras en relación con Dios. Una concierne al contexto dentro del cual se plantea el aparecer de Dios. Dios necesita del ser para manifestarse, y, por tanto, queda ligado a la excedencia del ser mismo que se sustrae. En relación con la cuestión del ser, Heidegger se refiere a "la sobreabundancia (die Überfülle), la excedencia (das Übermaß) de lo presente" y a "la dimensión de lo totalmente excesivo de la que surge la filosofía como "respuesta de un ser humano concernido por el excedencia de la presencialidad" ${ }^{\prime 37}$. En el despliegue de la verdad del ser se aventura y se arriesga "la preparación del aparecer del último Dios" ${ }^{\prime 38}$ cuyas señas al hombre del futuro a la vez destellan y se ocultan. Además, Heidegger se refiere a "el ser como Er-eignis que a partir de esta virante excedencia de sí mismo acontece y así se convierte en el origen de la contienda entre Dios y el hombre, entre el paso de Dios y la historia de los hombres" ${ }^{39}$. Como punto medio de encuentro entre el hombre y Dios, el Ereignis da lugar a una historia imprevisible: "El último Dios no es el fin sino el otro comienzo de inconmensurables posibilidades de nuestra historia" $^{40}$. Heidegger se refiere a una "historicidad de los que se pertenecen a partir de su pertenen-

\footnotetext{
35 Ibídem, pp. 26, 280.

36 Ibídem, p. 263.

37 M. Heidegger, Seminare (1951-1973), Gesamtausgabe 15, Frankfurt am Main, 1986, p. 331. Cfr. M. Heidegger, Beiträge zur Philosophie, p. 508. Aquí Heidegger habla de sobrepasamiento (Über-treffung).

38 M. Heidegger, Beiträge..., p. 411.

39 Ibid., p. 413.

40 Ibid., p. 411. Una dimensión de lo posible está implicada tanto en el Ereignis del ámbito ontológico como en el Advenimiento del Reino del ámbito de la fe. Por un lado, se encuentra el juego de ocultamiento y desocultamiento del ser, y la posibilidad de una manifestación más originaria al margen de la imposición técnica. Por el otro, se encuentra el juego de encubrimiento y manifestación del amor, y la posibilidad
} 
cia a Dios". Así, un pueblo recibe asignada su historia del Dios que "lo fuerza por encima de sí mismo" al instaurar "los caminos por los cuales se mueve más allá de sí", de modo que "solo entonces elude el peligro de girar en torno de sí mismo y de idolatrar como su incondicionado lo que solo son condiciones de su existencia" ${ }^{41}$.

Otra manera de considerar la excedencia atañe a la naturaleza misma del aparecer de Dios, es decir, a la protección de lo oculto en su ocultarse. Comentando a Hölderlin, Heidegger observa que el Dios que permanece desconocido es patente por medio del cielo, en el mundo como cuaternidad, es decir, como lugar de manifestación del ente en el cielo, la tierra, los divinos y los mortales, pero queda resguardado como desconocido: “El aparecer del Dios por medio del cielo consiste en un desvelar que deja ver aquello que se oculta, pero lo deja ver no en razón de que busca arrancar lo oculto a partir de su condición-de-oculto, sino solo en razón de que protege lo oculto en su ocultarse. Así aparece el Dios desconocido como el desconocido por medio de la patencia del cielo" 42 . En este sentido, Dios "tiene su extremadamente única unicidad y se encuentra fuera de toda determinación calculable" ${ }^{\prime 43}$.

En suma: Heidegger se ocupa de un acrecentamiento de posibilidades históricas que surgen en el marco de un contrabalanceo recíproco de ser y hombre, y de hombre y Dios, por la mediación del Ereignis. En este acaecer, tanto Dios como el ser y el Ereignis tienen una condición inaparente porque exhiben una excedencia que se sustrae a la manifestación.

\section{Modos de retorno}

\section{1. Ámbitos de excedencia}

En los primeros tramos de la fenomenología se encuentra el análisis de un acrecentamien-

\footnotetext{
de la transfiguración de un mundo injusto. Cfr. R. Kearney, "Heidegger, le possible et Dieu", en R. Kearney y J. S. O'Leary (eds.), Heidegger et la question de Dieu, Paris, Grasset, 1980, pp. 141-158.

41 Ibídem, p. $398 \mathrm{~s}$.

42 Heidegger, Vorträge..., ob. cit., p. 201.

43 Heidegger, Beiträge..., ob. cit., p. 411.
}

to que se desenvuelve en el terreno histórico de un despliegue ascendente de razón y amor, de una creciente espiritualización y vivificación, y de un acontecer que lleva a Dios y al hombre a lo que tienen de propio. En el llamado giro teológico de la fenomenología más reciente, el tema se presenta desde dos puntos de vista. El primero, que será tratado en este apartado, enfatiza determinados ámbitos o dimensiones privilegiadas de la excedencia, esto es, la intersubjetividad, la interioridad y el mundo.

2.1.1. Lévinas se refiere a un "acrecentamiento (accroissement)" 44 en relación con la responsabilidad por el otro. Al definir la responsabilidad por el otro como la estructura esencial, primera y fundamental de la subjetividad, Lévinas señala que estamos coordinados con el otro de manera pre-original, es decir, anterior a todo comienzo. Ilustra su posición con la afirmación de Dostoievski según la cual cada uno de nosotros es culpable delante de todos y por todos, y que cada uno lo es más que los otros, y la de Isaías: "Antes que me llamen, yo responderé" (Is $6524)$. Ambas fórmulas aluden a la responsabilidad en que cada uno se encuentra colocado en la pasividad de una asignación que tiene lugar a pesar suyo. Este "uno-para-otro" trae consigo una no indiferencia con relación al prójimo por la que no se borran la indeclinabilidad del sujeto y las diferencias entre el uno y el otro como en las situaciones en que esta relación es entendida simétricamente como reciprocidad.

Dios pasa y deja sus huellas en el unopara-otro de la responsabilidad que "se acrecienta infinitamente -infinito viviente- $[. . .]^{\prime \prime 4}$. Por eso Lévinas se refiere a la "infinición de lo infinito" 46 y a la "demasía (surplus) creciente de lo Infinito" ${ }^{\prime 4}$. La responsabilidad infinitamente creciente se asocia con una doble relación. Por un lado, en virtud de esta originalidad, la responsabilidad remite a lo Infinito porque no tiene origen o comienzo en el sujeto, sino que es

44 E. Lévinas, Du Dieu qui vient à l'idée, Paris, Vrin, 1982, p. 120.

45 E. Lévinas, Autrement qu'être ou au-delà de l'essence, Phaenomenologica 54, La Haye, Martinus Nijhoff, 1974, p. 218.

46 Ibídem, pp. 184 y ss.

47 E. Lévinas, $\mathrm{Du}$ Dieu..., ob.cit., p. 120. 
algo que le pasa sin que pueda dar cuenta de ello. Por el otro, la eminencia de lo Infinito apela a la responsabilidad que lo testimonia porque se hace interioridad en el testimonio en tanto "me concierne (concerne) y me cierne (cerne) y me ordena por mi voz misma" ${ }^{48}$. El testimonio es el modo en que lo Infinito se revela sin aparecer, es decir, el modo en que pasa por lo finito llamándolo o moviéndolo hacia sí: "Por la voz del testimoniante, la gloria de lo Infinito se glorifica" ${ }^{\prime 4}$.

Lévinas se refiere a un tiempo antes del tiempo en el sentido de "una anterioridad anterior a toda anterioridad representable" ${ }^{\prime \prime}$. La responsabilidad por el otro no está atada a un presente actual, y con ello a la sincronización por medio de un recuerdo, sino que se vincula con un tiempo diacrónico en que pasado y futuro tienen una significación ajena al presente. Hay un pasado irrecuperable por el recuerdo porque es inconmensurable con un presente en razón de ser ajeno a la voluntad subjetiva y, por ende, anterior a toda decisión tomada en un ahora. Y hay un futuro que no llegará a ser presente porque no es la anticipación de un porvenir sino la obligación infinita de una responsabilidad que obliga más allá de la muerte. Así, Lévinas pone en primer plano un "tiempo irreductible a presencia, pasado absoluto, irrepresentable" ${ }^{\prime 51}$, esto es, un "pasado inmemorial, significado sin haber sido presente, significado a partir de la responsabilidad 'para el otro' en que la obediencia es el modo propio de la escucha del mandamiento" ${ }^{\prime 52}$.

2. 1. 2. Henry habla de un "acrecentamiento de sí" y de una "fenomenalidad del acrecentamiento" ${ }^{\prime \prime 3}$ en el terreno de la interioridad. En primer lugar, señala que el saber de la conciencia, que es objetivo y revela otra cosa, tiene su condición ontológica de posibilidad en el saber

\footnotetext{
48 E. Lévinas, Autrement..., ob.cit., p. 187.

49 Ibídem, p. 186.

50 Ibídem, p. 157.

51 Ibídem.

52 E. Lévinas, Entre nous. Essais sur le penser-à-l'autre, Paris, Grasset, 1991, p. 191.

53 M. Henry, La barbarie, Paris, Grasset, 1987, pp. 176 y ss.
}

de la vida, es decir, en la autoafección o pura experiencia de sí en la inmanencia radical de la afectividad. Ningún acto revelaría algo si no se revelara primero a sí mismo. La autoafección de la vida define su vivir en tanto experienciarse a sí misma e implica una automanifestación. Henry caracteriza a la autoafección como pathos por su carácter afectivo y como carne porque se identifica con los poderes corporales en la actualidad de su ejercicio.

En segundo lugar, Henry distingue un concepto fuerte y un concepto débil de autoafección. Por un lado, de acuerdo con el concepto débil, la vida se autoafecta en el sentido de que padece por sí misma el contenido de su afección. Por otro lado, me soy dado a mí mismo sin que la donación proceda de mí. No me afecto sino que soy y me encuentro autoafectado. El sentido débil de autoafección remite al sentido fuerte de modo que se funda en él. La pasividad del sí-mismo singular no es solo la pasividad respecto de sí mismo en la autoafección sino ante todo la pasividad respecto del proceso eterno de autoafección de la Vida que lo engendra. El destino del hombre está inscrito en la relación recíproca del concepto fuerte y el concepto débil de autoafección, de la autoafección naturante y de la autoafección naturada: “El Sí-mismo singular se autoafecta, es la identidad del afectante y el afectado, pero esta identidad no la ha puesto él mismo. El Sí-mismo no se afecta sino porque la Vida absoluta se autoafecta en él" ${ }^{\prime 54}$.

La Vida absoluta es acósmica y eterna porque excluye de sí toda pertenencia al mundo y todo éxtasis temporal. Acontece como el movimiento de un eterno venir a sí misma en el que se engendra en cada caso el sí-mismo que yo soy como un sí-mismo singular. Henry introduce el concepto de lo Inmemorial para designar la antecedencia de la Vida respecto de todo viviente. La Vida nos ha unido a ella desde siempre y para siempre en una memoria sin memoria: “Esta memoria inmemorial de la vida, la que

54 M. Henry, C'est moi la vérité. Pour une philosophie du christianisme, Paris, Éditions du Seuil, 1996, p. 136. 
solo puede unirnos a la Vida, es la vida misma en su pathos: es nuestra carne" ${ }^{\prime \prime 5}$. La Vida precede al sí-mismo singular como una instancia sobre la cual no es posible volver, es decir, como un pasado absoluto que permanece cerrado para siempre. Por eso está fuera de toda memoria y se encuentra en el "Olvido de lo Inmemorial" 156 . Puesto que no es el reverso de un recuerdo posible, y de un olvido en sentido habitual, este pasado significa un olvido insuperable o absoluto. Henry se refiere a "lo Inmemorial, lo Archi-Antiguo que se sustrae a nuestro pensamiento -lo siempre ya olvidado, lo que se mantiene en un Archi-Olvido" ${ }^{57}$.

2.1.3. Heinrich Rombach se ocupa de una "autoelevación (Selbstübersteigung)" o "autotrascendencia (Selbstranszendenz)" 58 del mundo en términos de un acontecer puro que permanentemente va más allá de lo dado. Su antropología estructural se presenta no solo como una cosmología estructural sino también como una teología estructural. Las tres dimensiones remiten al mismo tema: el drama originario del acontecer puro. El todo de la vida, al que hasta ahora se ha llamado Dios, es "el conjunto del acontecer cósmico y "el ser más elevado, superior y más abarcador" ${ }^{29}$. El avance emergente por el que las cosas se trascienden -y tiene lugar la autogénesis de estructuras en la forma de un acontecer puro que no presupone un portador- se debe a la presencia del todo de la vida en ellas. Más que con la tradición de la filosofía occidental, la fenomenología estructural se encuentra en la cercanía de las religiones. Porque mitologías y religiones son interpretaciones dramáticas de la vida y el mundo frente a las cuales la filosofía adolece de formalismo. Tales interpretaciones comprenden en forma más precisa la cuestión ya que, "por ejemplo, la Vita Christi es ya casi una fenomenología infalible del acontecer puro" ${ }^{\prime 60}$.

55 M. Henry, Incarnation. Une philosophie de la chair, Paris, Éditions du Seuil, 2000. p. 267.

56 Michel Henry, Phénoménologie de la vie. Tome IV : Sur l'éthique et la religion, Paris, Presses Universitaires de France, 2004, pp. 190, 194.

57 Henry, C'est moi la vérité, p. 208

58 H. Rombach, Strukturanthropologie "Der menschliche Mensch", Freiburg/München, Karl Alber, 1987, p. 206.

59 Ibídem, p. 279.

60 Ibídem, p. 277.
Teniendo en cuenta que la idemidad implica una armonía o unión que es más que la unidad característica de la identidad, Rombach resume el pensamiento estructural en la siguiente fórmula: "La identidad de lo finito es idémica con la identidad de lo infinito" $61 . \mathrm{Ob}$ serva que no se debe hablar de un Dios "más allá" del mundo sino "en" el mundo o "como" mundo. Si se lo concibe como "más allá" y "junto" al mundo, Dios contrapondría a lo finito y dependería del mundo para su determinación o definición. Por un lado, lo infinito no es algo que se encuentre frente a y sobre lo finito porque este tipo de existencia es lo que caracteriza a lo finito. Por el otro, en virtud de que la autotrascendencia es inherente a las cosas, el mundo es más que un compuesto de cosas finitas y la infinitud no es la suma de las cosas finitas. De este modo, Rombach busca un sentido en que un buen "teísmo" no se contrapone a un buen "panteísmo". Se debe rechazar la diferenciación ontológica entre finitud e infinitud porque el mundo pertenece a Dios: “Dios no puede excluir nada, ni siquiera el mundo, y, por ende, el mundo le pertenece y él no puede ser algo 'otro' que el mundo" 62 A fin de no ser pensada en forma mundana, la trascendencia de Dios necesita de un sentido propio e inderivable que solo se puede entender a partir de Él mismo, y que, por tanto, tiene el carácter del "por-sí-mismo" (Von-selbst). Aquello que trasciende lo finito no es algo que existe ante nosotros sino lo que acontece "si este acontecer -aclara Rombach-no es pensado como apéndice de lo existente, sino como su origen, como 'avance emergente', como 'acontecer puro'" $^{\prime \prime 63}$. Dios es pensado a partir de sí mismo como lo omniabarcador, la fuente y el origen de todas las situaciones, y el conjunto del acontecer cósmico puro. Seres humanos y cosas remiten a lo creador que carece de nombre y estructura y sin embargo tiene una fuerza suprema: "Esto creador es el 'Dios que viene', como lo ha llamado Hölderlin. El Dios que viene es en el venir. Él es tan solo en tanto es en el venir" ${ }^{\prime \prime 6}$.

61 H. Rombach, Der Ursprung. Philosophie der Konkreativität von Mensch und Natur, Freiburg im Breisgau, Rombach, 1994, p. 175).

62 Ibídem

63 H. Rombach, Der kommende Gott. Hermetik - eine neue Weltsicht, Freiburg im Breisgau, Rombach, 1991, p. 104.

64 Ibídem 
El todo de la realidad se desenvuelve en un presente viviente o intemporal, es decir, en la eternidad: "El tiempo, en esta forma de la unidad, como presente, es eternidad" 65 . De modo que el tiempo que fluye se asocia con estructuras parciales que se desprenden del todo de la vida, y cada estructura implica un ahora en el que se ingresa y del que se sale para ingresar en otra estructura parcial. Todo presente pasajero es una perspectiva temporal que mediatiza el presente viviente o eterno.

2.1.4. Estas tres posiciones convergen en torno de un sobrepasamiento de la intersubjetividad, la subjetividad y el mundo. Por las tres vías, a través de las infinitudes asociadas con la responsabilidad, la autoafección y el acontecer puro, aparece la cuestión teológica. Y en cada caso se proporciona también una versión de una dimensión anterior al tiempo sincrónico, extático o pasajero. A la descripción de la excedencia inherente a un particular ámbito sigue luego el análisis tanto de un modo de participación de Dios como de una relación con la eternidad.

\subsection{La excedencia como sobreabundancia y saturación}

El tema de la excedencia recibe también un tratamiento que no concierne tanto a un determinado ámbito de la realidad cuanto al enfoque dirigido a los fenómenos y a su condición misma en tanto fenómenos. Así, Ricoeur establece un contraste entre lógica de la sobreabundancia y lógica de la equivalencia, y Marion destaca la revelación como el fenómeno de máxima saturación.

2.2.1. Ricoeur señala que "la religión tiende a colocar toda experiencia [...] en la perspectiva de la economía del don"66 de manera que es el "sentimiento de pertenecer a una economía del don, con su lógica de la sobreabundancia, irreductible a una lógica de la equivalencia" ${ }^{67}$.

\footnotetext{
65 Ibídem, p. 161.

66 P. Ricoeur, Lectures 3. Aux frontières de la philosophie, Paris, Éditions du Seuil, 1994, p. 276.

67 Ibídem, p. 263.
}

La lógica de la sobreabundancia contrasta, como una lógica divina de la excedencia, con la lógica de los hombres en tanto lógica de la equivalencia $^{68}$. La oposición se manifiesta, por ejemplo, en la relación entre el amor y la justicia. Por un lado, la lógica de la equivalencia se expresa en la igualdad de todos ante la ley, trata en forma análoga los casos análogos, y procura reciprocidad y reversibilidad entre el agente y el paciente. Por otro lado, la lógica de la sobreabundancia aporta un motivo nuevo más allá de la lógica de la equivalencia: el obrar por amor al prójimo. Su función es elevar el sentido de la justicia y dar expresión a la generosidad en el nivel de las instituciones a través de excepciones. Así, mediante una correlación que no renuncia a las características de cada polo, Ricoeur propone "tender un puente entre la poética del amor y la prosa de la justicia" 69 .

La lógica de la sobreabundancia se expresa en el Nuevo Testamento en el discurso de la parábola, el proverbio y la exhortación. Son los géneros literarios utilizados por Jesús en su enseñanza. Estas formas de discurso exhiben una lógica del sentido que reposa sobre el uso de expresiones-límites que llevan a cabo una ruptura y transgresión respecto del lenguaje y la vida cotidiana. Por ejemplo, las parábolas significan el Reino por la extravagancia de lo extraordinario en lo ordinario. Describen comportamientos excéntricos respecto de la vida cotidiana a la que por lo demás se ajustan. La refiguración específica de la parábola difiere de la que caracteriza en general al lenguaje poético porque se realiza en dirección a lo extremo, esto es, en función de algo más. Esto significa que introduce en la intriga un rasgo insólito y escandaloso al jugar con el contraste entre el realismo de la historia y la extravagancia del desenlace: "Este 'derrape' de la historia es el secreto del género 'parábola'. La palabra significa el Reino precisamente por ese rasgo de extravagancia que la hace estallar fuera de su cuadro"70. Respecto

68 Cfr. P. Ricoeur, "La logique de Jésus. Romains 5", Études Théologique et Religieuses, 55, № 3, 1980, pp. 420-425; y Lectures 3, ob. cit., p. 173.

69 P. Ricoeur, Liebe und Gerechtigkeit (Amour et justice), Tübingen, J. C. B. Mohr (Paul Siebeck), 1990, p. 40.

70 Ibídem, p. 17. 
del creyente frente al texto bíblico, y del círculo de creer para comprender y comprender para creer, Ricoeur se refiere a una apuesta o suposición de sentido y de una transferencia del texto a la vida en la que "lo que haya arriesgado me será devuelto centuplicado en las formas de un acrecentamiento (surcroît) de inteligencia, valor y alegría"71.

2.2.2. Marion traza una tópica de diferentes tipos de fenómenos. El hilo conductor de la tópica es el grado de intuición. Distingue tres figuras originales de la fenomenalidad según su tenor de donación. El menor tenor se encuentra en los fenómenos pobres de intuición en que la intención significativa anticipa la intuición. Y la intuición no es la intuición real de lo individual sino la intuición de objetos lógicos y la intuición de esencias. Tienen el privilegio de la certeza, pero también un déficit porque escapan a lo individual y temporal. En segundo lugar se encuentran los fenómenos de derecho común en que la intención significativa también preve la intuición que en este caso es individual. Hay una plenificación intuitiva de un significado mediante una intuición real de un individuo sin que su horizonte pueda ser excedido por la plenificación. Son los objetos del mundo percibido, las ciencias de la naturaleza y la técnica. Por último, se encuentran los fenómenos saturados en que la intuición se acrecienta al punto en que sobrepasa la intención significativa de tal manera que no puede ser prevista. La intuición se libera de la intención significativa, y el yo de la intencionalidad no puede constituir la intuición en un objeto definido por un horizonte. Hay "un exceso de intuición, y, por tanto, un exceso de donación", es decir, una "sobreabundancia intuitiva"72. Marion presenta una tópica del mismo fenómeno saturado y distingue cuatro tipos, es decir, paradojas que no pueden constituirse como objetos dentro de un horizonte de anticipación. Además del acontecimiento histórico y la obra de arte o ídolo, Marion menciona la autoafección de la vida o carne en el sentido de Henry y el rostro del otro en el sentido de Lévinas.

71 Ricoeur, Lectures 3..., ob. cit., p. 282.

72 Marion, Étant donné..., ob. cit., pp. 278 y ss.
Aquí se plantea el problema de si tiene sentido considerar un fenómeno que se da según un máximo de saturación. Marion declara que esta posible figura de la fenomenalidad debe responder a la caracterización general de la fenomenalidad, y a la vez esbozarse como posibilidad última independientemente de toda realización efectiva e intramundana. Estas exigencias se satisfacen en el fenómeno de la revelación. En primer lugar, se trata de la última variación posible de la fenomenalidad del fenómeno en tanto dado: “[...] el fenómeno de la revelación no solo depende de la saturación (paradoja en general), sino que concentra solo en él los cuatro tipos de fenómenos saturados y se da a la vez como acontecimiento histórico, como ídolo, como chair y como ícono (rostro). Se trata ciertamente de una saturación de quinto tipo [...] porque confundiéndolos en él, satura la fenomenalidad en el segundo grado, por saturación de saturación"73. En segundo lugar, el fenómeno de la revelación es una simple posibilidad. Se lo describe a través de una figura precisa, pero sin presuponer su efectividad. Si bien la fenomenología no puede decidir nada acerca del darse de la revelación, "ella (y ella sola) puede fijar que, en este caso, un tal fenómeno de revelación debería adoptar la figura de la paradoja de las paradojas: [...] siguiendo una ley de esencia de la fenomenalidad"74.

2.2.3. Ya sea a través de una perspectiva que permite apreciar toda nuestra experiencia de otra manera, ya sea a través del análisis de los rasgos fundamentales que presentan determinados fenómenos, entre los cuales se encuentran los examinados en el apartado anterior, la fenomenología pone en primer plano excedencias y acrecentamientos y en ambos casos los encamina hacia una visión religiosa.

\section{Bibliografía}

Diemer, A., Edmund Husserl. Versuch einer systematischen Darstellung seiner Phanomenologie, Meisenheim am Glan, Anton Hain, 1956.

73 Ibídem, p. 327.

74 Ibídem, pp. 327 y ss. 
Duméry, H., Critique et religion. Problèmes de méthode en philosophie de la religion, Paris, Societé d'Édition d'Enseignement Supérieur, 1957.

Duméry, H., Philosophie de la religion. Essai sur la signification du christianisme. II: Catégorie de foi, Paris, Presses Universitaires de France, 1957.

Heidegger, M., Wegmarken (1919-1961), Gesamtausgabe 9, Frankfurt am Main, Vittorio Klostermann, 1976.

Heidegger, M., Unterwegs zur Sprache (1950-1959), Gesamtausgabe 12, Frankfurt am Main, Vittorio Klostermann, 1985.

Heidegger, M., Seminare (1951-1973), Gesamtausgabe 15, Frankfurt am Main, Vittorio Klostermann, 1986.

Heidegger, M., Beiträge zur Philosophie (Vom Ereignis) (1936-1938), Gesamtausgabe 65, Frankfurt am Main, Vittorio Klostermann, 1989.

Heidegger, M., Vorträge und Aufsätze (19361953), Gesamtausgabe 7, Frankfurt am Main, Vittorio Klostermann, 2000.

Heidegger, M., Identität und Differenz, Gesamtausgabe 11, Frankfurt am Main, Vittorio Klostermann, 2006.

Henry, M., La barbarie, Paris, Grasset, 1987.

Henry, M., C'est moi la vérité. Pour une philosophie du christianisme, Paris, Éditions du Seuil, 1996.

Henry, M., Incarnation. Une philosophie de la chair, Paris, Éditions du Seuil, 2000.

Henry, M., Phénoménologie de la vie. Tome IV : Sur l'éthique et la religion, Paris, Presses Universitaires de France, 2004.

Husserl, E., Erste Philosophie (1923/24). Erster Teil: Kritische Ideengeschichte, edición de R. Boehm, Husserliana VII, Den Haag, Martinus Nijhoff, 1956.
Husserl, E., Erste Philosophie (1923/24). Zweiter Teil: Theorie der phänomenologischen Reduktion, edición de R. Boehm, Husserliana VIII, Den Haag, Martinus Nijhoff, 1959.

Husserl, E., Zur Phänomenologie der Intersubjektivität. Texte aus dem Nachlass. Zweiter Teil: 1921-1928, edición de I. Kern, Husserliana XIV, Den Haag, Martinus Nijhoff, 1973.

Husserl, E., Zur Phänomenologie der Intersubjektivität. Texte aus dem Nachlass. Dritter Teil: 1929-1935, edición de I. Kern, Husserliana XV, Den Haag, Martinus Nijhoff, 1973.

Husserl, E., Aufsätze und Vorträge (19221937). Mit ergänzenden Texten, edición de Th. Nenon y H. Rainer Sepp, Husserliana XXVII, Dordrecht/Boston/London, Kluwer Academic Publishers, 1989.

Husserl, E., Briefwechsel, Husserliana-Dokumente III, edición de K. Schumann y E. Schuhmann, Dordrecht/Boston/London, Kluwer Academic Publishers, 1999.

Kearney, R., "Heidegger, le possible et Dieu", en R. Kearney y J. S. O'Leary (eds.), Heidegger et la question de Dieu, Paris, Grasset, 1980, pp. 125-167.

Kern, I., Husserl und Kant, Phaenomenologica 16, Den Haag, Martinus Nijhoff, 1964.

Lévinas, E., Autrement qu'être ou au-delà de l'essence, Phaenomenologica 54, La Haye, Martinus Nijhoff, 1974.

Lévinas, E., Du Dieu qui vient à l'idée, Paris, Vrin, 1982.

Lévinas, E., Entre nous. Essai sur le penserà-l'autre, Paris, Grasset, 1991.

Marcel, G., Essai de philosophie concrète, Paris, Gallimard, 1967.

Marcel, G., Le mystère de l'être, Paris, Association Présence de Gabriel Marcel, 1997. 
Marion, J.-L., Étant donné. Essai d'une phénoménologie de la donation, Paris, Presses Universitaires de France, 1997.

Patocka, J., Le monde naturel et le mouvement de l'existence humaine, Phaenomenologica 110, traducción de E. Abrams, prefacio de H. Declève, Dordrecht/Boston/London, Kluwer Academic Publishers, 1988.

Ricoeur, P., "La logique de Jésus. Romains 5", Études Théologiques et Religieuses, 55, № 3, 1980, pp. 420-425.

Ricoeur, P., Liebe und Gerechtigkeit (Amour et justice), Tübingen, J. C. B. Mohr (Paul Siebeck), 1990.

Ricoeur, P., Lectures 3. Aux frontières de la philosophie, Paris, Éditions du Seuil, 1994.

Rombach, H., Strukturanthropologie "Der menschliche Mensch", Freiburg/ München, Karl Alber, 1987.
Rombach, H., Der kommende Gott. Hermetik - eine neue Weltsicht, Freiburg im Breisgau, Rombach, 1991.

Rombach, H., Der Ursprung. Philosophie der Konkreativität von Mensch und Natur, Freiburg im Breisgau, Rombach, 1994.

Scheler, M., Späte Schriften, Gesammelte Werke 9, Bern/München, Francke, 1976.

Scheler, M., Schriften aus dem Nachlass, Band 2: Erkenntnislehre und Metaphysik, Gesammelte Werke 11, Bern/München, Francke, 1979.

Strasser, S., "Das Gottesproblem in der Spätphilosophie Husserls", Philosophisches Jahrbuch der Görres-Gesellschaft, 67, 1959, pp.130-142.

Toulemont, R., L'essence de la societé selon Husserl, Paris, Presses Universitaires de France, 1962. 